\title{
Timing of GLP-1 Receptor Agonist Initiation for Treatment of Type 2 Diabetes in the UK
}

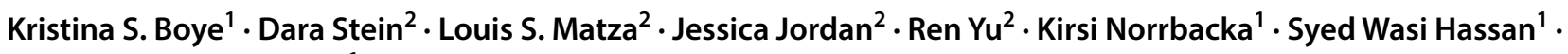 \\ Luis-Emilio García-Pérez ${ }^{1}$
}

Published online: 21 May 2019

(c) The Author(s) 2019

\begin{abstract}
Introduction Patients with type 2 diabetes mellitus (T2DM) who fail to meet glycaemic control are at increased risk of diabetes complications. For patients who cannot maintain glycaemic control with oral medication, one recommended option is to add an injectable glucagon-like peptide-1 receptor agonist (GLP-1 RA) to their treatment regimen. The purpose of this study was to examine time to treatment intensification with GLP-1 RAs, including the duration of time that patients did not maintain glycaemic control with oral medication.

Methods This was a medical record review conducted in the UK via a physician survey. Patients eligible to have their records reviewed were required to be $\geq 18$ years of age, have a confirmed T2DM diagnosis, and have initiated GLP-1 RA treatment for T2DM in the past 6 months. All glycated haemoglobin (HbA1c) values within 5 years prior to GLP-1 RA initiation were collected.

Results A total of 113 physicians contributed data for 1096 patients (mean age at the time of GLP-1 RA initiation was 54.9 years, $55.4 \%$ were male, and $71.4 \%$ were White). Median time from T2DM diagnosis to GLP-1 RA initiation was 6.1 years. Median consecutive time patients taking oral regimens were not under glycaemic control (HbA1c $>7.0 \%)$ prior to GLP-1 RA initiation was 13.5 months. Patients treated by general practitioners (GPs) had a significantly longer duration of time with insufficient glycaemic control prior to GLP-1 RA initiation compared with patients treated by diabetes specialists (median time for specialists was 11.0 months vs. 17.0 months for GPs; $p=0.038$ ).

Conclusions Results suggest that treatment intensification is often delayed despite consistently poor glycaemic control for more than 12 months, contrary to treatment guideline recommendations. Findings from this study highlight that some T2DM patients may benefit from more rapid treatment intensification, which could improve glycaemic control and reduce the risk for many short- and long-term health complications.
\end{abstract}

\section{Introduction}

Guidelines for treatment of type 2 diabetes recommend intensifying therapy for patients whose oral treatment regimens do not provide adequate glycaemic control [1-5]. More

Louis S. Matza

louis.matza@evidera.com

Kristina S. Boye

boye_kristina_secnik@lilly.com

Dara Stein

dara.stein@evidera.com

Jessica Jordan

jessica.jordan@evidera.com

Ren Yu

ren.yu@evidera.com intensive treatment regimens often include the addition of injectable medications such as insulin or a glucagon-like peptide-1 receptor agonist (GLP-1 RA). Despite these recommendations, a range of studies suggest that patients and medical professionals may be reluctant to initiate these

Kirsi Norrbacka

norrbacka_kirsi@lilly.com

Syed Wasi Hassan

hassan_syed_wasi@lilly.com

Luis-Emilio García-Pérez

garcia_luis-emilio@lilly.com

1 Eli Lilly and Company, Indianapolis, IN, USA

2 Patient-Centered Research, Evidera, 7101 Wisconsin Avenue, Suite 1400, Bethesda, MD 20814, USA 


\section{Key Points}

The median consecutive time that patients on oral regimens were not under glycaemic control (HbA1c > 7.0\%) prior to GLP-1 RA initiation was 13.5 months.

These results suggest that treatment intensification is often delayed despite consistently poor glycaemic control, contrary to treatment guideline recommendations.

Findings from this study highlight that there may be patients with type 2 diabetes who would benefit from more rapid treatment intensification, which could improve glycaemic control and reduce the risk for many short and long-term health complications.

injectable treatments despite their potential health benefits [6-13]. This reluctance to initiate or intensify therapy is often called clinical inertia, and it can have serious consequences, including increased risk for poor glycaemic control and a resulting range of diabetes-related complications [14-17].

A substantial body of research has examined reasons for clinician inertia and patient reluctance related to initiation of insulin therapy. For example, clinicians may be reluctant to prescribe insulin due to expectations of patient noncompliance, fear of hypoglycaemia, and beliefs that patients may not want to use an injectable treatment [14, 18-20]. Furthermore, patients have described reluctance to initiate insulin, resulting from fear of injections and hypoglycaemia as well as concerns about potential lifestyle restrictions and weight gain $[6,11,12,21]$. In addition, studies in large samples of patients have examined the duration of delays in treatment intensification with insulin $[9,22]$. A recent systematic review of five of these studies found that treatment intensification was often delayed by over 1 year despite failure to achieve target glycated haemoglobin (HbA1c) measurements [15].

Findings from a recent clinician survey suggest that similar inertia may exist for injectable GLP-1 RAs [23]. This class of treatment for type 2 diabetes patients is often a recommended addition to a treatment regimen when oral or insulin medication alone does not result in sufficient glycaemic control [1-4, 24, 25]. Despite GLP-1 RA efficacy for glycaemic control and potential weight loss benefits [24, 26-28], the clinician survey identified reasons for clinical inertia [23]. Clinicians reported several factors that caused hesitation when prescribing this medication class, including GLP-1 RAs not being the recommended first-line therapy according to treatment guidelines, the injectable route of administration, the cost, and the risk of gastrointestinal adverse effects. In addition, almost one-quarter of general practice physicians reported not having sufficient knowledge to prescribe a GLP-1 RA.

Although these physician perceptions suggest that GLP-1 RAs may be associated with clinical inertia similar to that of insulin, no studies have examined the extent of this inertia. For example, no published information was located regarding the duration of time patients remain on oral medications prior to initiating treatment with GLP-1 RAs, including circumstances where escalation to injectable treatment may provide treatment benefit. Therefore, the purpose of this study was to examine the timing of GLP-1 RA initiation in patients with type 2 diabetes via a retrospective review of patient medical records. Analyses focused on the duration of time from diagnosis to GLP-1 RA initiation, as well as the length of time patients remained on oral medication without achieving glycaemic control prior to GLP-1 RA initiation.

\section{Methods}

\subsection{Overview of Study Design}

Data were collected from physicians who treat patients with type 2 diabetes mellitus (T2DM) in the UK. Each physician completed online data collection forms to report their own professional background, as well as information from medical records for approximately 10 patients who initiated treatment with a GLP-1 RA in the past 6 months. Patient medical chart data included demographics, medical history, T2DM diagnosis date, most recently added T2DM treatment regimen, GLP-1 RA type and date of GLP-1 RA initiation, and blood glucose levels (i.e. HbA1c measurements) over the 5 years prior to GLP-1 RA initiation.

The online survey, medical record review, and subsequent analysis was designed to explore two questions. First, analyses were conducted to examine the time from diagnosis of T2DM to initiation of the first GLP-1 RA (illustrated in Fig. 1). Similar results have been reported for insulin [9, 20], and this is the first known study examining this question in relation to GLP-1 RAs. Second, analyses examined the duration of time prior to GLP-1 RA initiation that patients received oral treatment without achieving glycaemic control (illustrated in Fig. 2). This second analysis provides

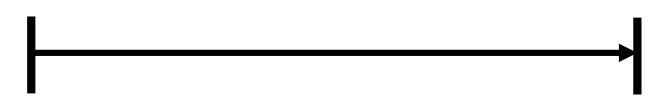

Date of Type 2

Diabetes Diagnosis

Date of GLP-1

RA Initiation

Fig. 1 First objective: duration of time from type 2 diabetes diagnosis to GLP-1 RA initiation. GLP-1 glucagon-like peptide-1, $R A$ receptor agonist 
Fig. 2 Second objective: duration of clinical inertia (i.e. duration of time oral-treated patients had $\mathrm{HbA} 1 \mathrm{c}$ values indicating inadequate glycaemic control before GLP-1 RA initiation). $G L P$-1 glucagon-like peptide-1, $H b A 1 c$ glycated haemoglobin, $R A$ receptor agonist

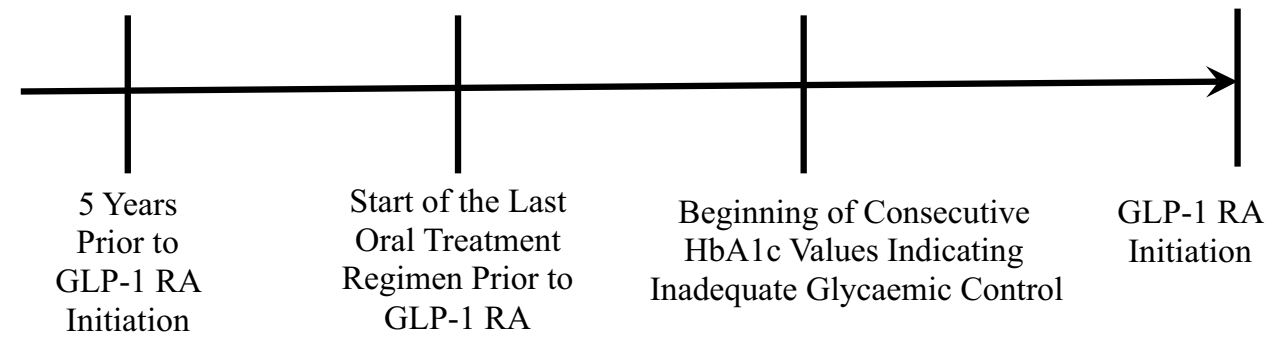

A insight into clinical inertia prior to GLP-1 RA initiation. Again, similar data have been presented for clinical inertia related to initiation of insulin treatment $[9,29]$, but this is the first study to address this issue in relation to GLP-1 RA treatment.

\subsection{Inclusion Criteria and Recruitment Process for Physicians}

Since treatment patterns in the UK may differ based on physician background, training, and medical specialty, an effort was made to recruit a diverse range of physicians categorized into one of three groups. Group 1 consisted of diabetes specialists (i.e. endocrinologists and diabetologists); group 2 included general practitioners with a special interest (GPwSI) in diabetes; and group 3 consisted of general practitioners (GPs) with no special interest in diabetes. Targets for the three physician groups were determined prior to data collection to ensure a broad range of physician backgrounds were represented. All physicians were required to (1) have one of the following medical degrees: MBBS, MBChB, MRCP, MRCGP, FRCP, or MD; (2) be currently licensed to practice in the UK; (3) see at least five patients with T2DM per month; and (4) have initiated GLP-1 RA treatment with a minimum of 10 patients for the treatment of T2DM over the 6 months prior to completing the survey.

Physicians who could potentially meet the above criteria were identified from a database of physicians who had pre-enrolled to participate in research. During this preenrollment, physicians agreed to have some of their personal details and contact information stored in the database so that they could be contacted for future research projects. The database included details on physician specialty (e.g. endocrinologists, diabetologists, GPs) and geographic location within the UK so that a sample could be recruited that was diverse in terms of medical specialty and geographical location. The physicians were contacted via email invitations and telephone outreach in full compliance with good practices described by UK laws and other UK healthcare organizations (e.g. National Health System [NHS], Health Research Authority [HRA], Association of the British Pharmaceutical Industry [ABPI], Prescription Medicines Code of Practice Authority [PMCPA]).

\subsection{Inclusion Criteria for Patients with Type 2 Diabetes}

Although no patients directly participated in this study, there were patient criteria used to determine whether patient medical record data were eligible for inclusion. Each physician was asked to complete a data collection form for the 10 most recent patients who met all of the following inclusion criteria: (1) medical record documentation of T2DM diagnosis; (2) medical record documentation of T2DM diagnosis date; (3) at least 18 years of age at the time of initiating GLP-1 RA; and (4) initiated treatment with a GLP-1 RA for T2DM in the 6 months prior to the physician's survey completion date. This must have been the first time the patient was treated with any GLP-1 RA. For example, if the physician completed the survey on 1 July 2017 , patients may be included if they initiated their first GLP-1 RA between 1 January and 1 July 2017. Patients were excluded if they had (1) participated in any clinical trials within the 5 years prior to GLP-1 RA initiation, or (2) been treated with a GLP-1 
RA for a condition other than T2DM (e.g. weight loss or treatment of obesity).

\subsection{Online Data Collection Forms}

The online data collection forms were developed specifically for use in this study. First, information about the study was presented and physicians provided their electronic consent (e-consent). Then, a series of questions asked physicians to report information regarding their professional background and experience treating patients with T2DM. These questions were used to confirm that physicians met the study inclusion criteria, while gathering information to characterize the sample and categorize each physician within one of the three groups (i.e. diabetes specialists, GPwSIs, or GPs). Examples of questions included: "What is your medical degree?"; "On average, how many type 2 diabetes patients do you see in a typical month?"; "During the past 6 months, how many of your patients have you initiated on GLP-1 RA treatment for type 2 diabetes?"; and "Please select the geographic region where your main practice is located".

After completing the series of questions on their own background, the physicians responded to questions about their patients' history by referring to patient medical records for retrospective information on GLP-1 RA initiation, other types of diabetes treatments, HbA1c measurements, demographics, and other clinical characteristics. Examples of questions included: "When was the patient diagnosed with type 2 diabetes?"; "When was the patient first prescribed a GLP-1 receptor agonist (RA)?"; "Please record all the patient's HbA1c values and dates of HbA1c measurements for the 5 years prior to initiating GLP-1 RA treatment for type 2 diabetes"; and "What was the last type of diabetes regimen prescribed before the GLP-1 RA initiation?"

\subsection{Data Collection Procedures}

The study protocol and procedures were reviewed and approved by an Institutional Review Committee (Ethical and Independent Review Services IRB; 23 May 2017; Protocol 17059-01). The online data collection occurred from June to October 2017 using the data collection forms described above. The physicians completing the surveys were blinded to the study sponsor to avoid biasing their responses.

Potentially eligible physicians were sent invitation emails with instructions describing how to complete the survey online, and a link to their unique online data collection form. After clicking on this link, they entered the survey. When beginning the survey, the physicians were permitted to pause at any time and later resume at the point where they paused by using the link originally provided. Physicians who were delayed in completing the survey or who did not complete all contents of the survey in one session were encouraged to complete their data collection forms via email and/or phone reminders. As described above, the online survey proceeded according to the following steps: (1) electronic consent; (2) questions on physician background to determine eligibility and characterize the sample; and (3) questions about their eligible patients to be completed based on information in the medical records.

\subsection{Pilot Study}

Data from the first 11 physicians (four from group 1, three from group 2, and three from group 3) were examined as a pilot sample prior to continuing with the full study. After these physicians entered their data, the data collection was paused for an interim analysis to confirm that the online forms were clear and comprehensible. The 11 physicians reported data from a total of 97 patient medical charts (nine physicians entered ten charts, one entered four charts, and one entered three charts). After completing the data collection forms, these 11 pilot physicians were asked open-ended questions about their experience completing the survey (e.g. "Overall, did you think the online data collection forms were easy to complete?"; "Were there any questions or terminology that you found unclear or confusing?"; "Were there any data elements that you had a difficult time finding in the patients' charts?"; "Did you have any technical issues when navigating the website?").

Nine of the 11 physicians reported that the data collection forms were easy to complete. The remaining two participants indicated that the forms were long (e.g. 'long and fiddly', 'very time-consuming'), but they did not report concerns about clarity. In response to the other pilot study questions, no physicians reported any problems or issues. Because edits made to the data collection forms following the pilot study were very minor, with no changes to the content of the questions, the data from the physicians in the pilot sample were included in the final data analysis sample.

\subsection{Statistical Analysis Procedures}

Statistical analyses were performed using SAS version 9.4 (SAS Institute, Cary, NC, USA). Analyses were primarily descriptive, with the goal of identifying trends in timing of GLP-1 RA initiation. All analyses are presented for the total sample as well as separately for the three physician subgroups (e.g. diabetes specialists, GPwSIs, GPs). Descriptive data on participating physicians and the patients whose data were extracted from medical records are presented as frequencies and percentages for categorical variables, and means and standard deviations (SDs) for continuous variables. Differences between the three physician groups were examined using analysis of variance (ANOVA) for 
continuous variables, Chi-square tests for categorical demographic variables, and log-rank tests for median durations of time to GLP-1 RA initiation. Scheffe's post hoc adjustment was used to adjust for multiple pairwise comparisons when overall ANOVA models were significant.

Although physicians were asked to report the exact date of diagnosis, this date was unavailable for some patients. When both the day and month were missing, if the year was the same as the year of GLP-1 RA initiation, then the day and month of GLP-1 RA initiation was assigned to the missing fields. If the year of diagnosis was before the year of GLP-1 RA initiation, then 31 December was assigned to the missing fields. When the month and year were reported, but the specific day was unknown, if the month was the same as the month of GLP-1 RA initiation, then the date of GLP-1 RA initiation was assigned to the missing diagnosis day. If the month was before the month of GLP-1 RA initiation, then the last day of the month was assigned as the diagnosis day.

The final analysis focused on clinical inertia associated with GLP-1 RA initiation. The purpose of this analysis was to examine the duration of time patients had inadequate glycaemic control while treated with an oral regimen prior to intensifying treatment by initiating a GLP-1 RA. Based on $\mathrm{HbA1c}$ measurements, patients were categorized as having blood glucose levels that were in control or not in control. Because recommendations vary regarding $\mathrm{HbA} 1 \mathrm{c}$ values that indicate inadequate glycaemic control and the need for treatment intensification [4], two cut-offs were used to categorize patients as not in control: (1) $>7.0 \%$ or $53 \mathrm{mmol} /$ $\mathrm{mol}$; and (2) $>7.5 \%$ or $58 \mathrm{mmol} / \mathrm{mol}$. For this analysis, up to 5 years of $\mathrm{HbA} 1 \mathrm{c}$ data prior to GLP-1 RA initiation were reported for each patient, depending on the availability of these measurements in the patient's medical records.

For this analysis of inertia, several steps were followed. First, the time from starting the last oral treatment regimen prior to the GLP-1 RA to initiation of the first GLP-1 RA was calculated. Second, HbA1c values during treatment with the last oral regimen were examined to identify a point at which the patient could be considered not in control without any subsequent in-control HbA1c values prior to GLP-1 RA initiation (i.e. the first value $>7.0 \%$ or $7.5 \%$ without any subsequent values $<7.0 \%$ or $7.5 \%$ ). Third, the time from the start of this period of having over-target (i.e. $>7.0 \%$ or 7.5\%) $\mathrm{HbA} 1 \mathrm{c}$ values to the date of GLP-1 RA initiation was calculated.

For the analyses described above, the time to initiation of a GLP-1 RA is presented as both mean and median. In addition, this duration of time was analysed using the Kaplan-Meier (KM) method (including 95\% CIs for median and quartiles), which is reported graphically. The KM estimator for time-to-event data is a non-parametric statistic used to estimate the probability that the event of interest will occur after a certain time. A graph of the KM estimator is a series of declining horizontal steps that approximates the true probability function for the population of interest.

\section{Results}

\subsection{Physician Characteristics}

A total of 228 physicians agreed to participate, of whom $217(95.2 \%)$ accessed the online survey, including $19(8.3 \%)$ who did not agree to participate, $16(7.0 \%)$ who initiated fewer than 10 patients taking a GLP-1 RA during the past 6 months, 65 (30.0\%) who provided incomplete data, and 117 (53.9\%) who provided complete data. Four of the physicians (including one physician from the pilot study subgroup) who provided complete data were excluded from the study due to data quality concerns (e.g. duplicated data across patients and/or clinically implausible data). Therefore, a total of 113 (96.6\%) physicians contributed medical record data to the analysis dataset.

The final sample of physicians included 44 diabetes specialists (38.9\%), 23 GPwSIs (20.4\%), and 46 GPs (40.7\%) (Table 1). On average, the physicians reported that they had been health care providers for 19.0 years (SD 5.8) and treating patients with T2DM for 16.3 years (SD 5.2). Of the three physician groups, the specialists reported seeing the most patients with T2DM per month (mean of 136.0 per month vs. 103.5 for GPwSIs [ $p=0.0380]$ and 86.7 for GPs $[p<0.0001])$. Specialists also prescribed GLP-1 RAs to a significantly greater number of patients in the 6 months prior to completing the survey compared with the other two groups of physicians, with specialists reporting initiating GLP-1 RA treatment for an average of 81.0 patients, in contrast to 28.8 and 22.6 patients for the GPwSIs and GPs, respectively $(p<0.0001)$. A smaller proportion of physicians was from Scotland and Northern Ireland compared with the other regions. On average, each physician reported medical record data for 9.7 patients.

\subsection{Patient Characteristics}

Physicians contributed medical record data for a total of 1115 patients. However, during data review and cleaning, it appeared that 19 patient medical records (1.7\%) included potentially inaccurate data, and were therefore excluded from the final analysis. Two main types of errors were identified: (1) date of diagnosis equal to the date of GLP-1 initiation $(n=6)$; and (2) start date of the medication regimen prior to the GLP-1 RA was the same as (or within 7 days of) the date of GLP-1 RA initiation $(n=13)$. Therefore, data from 1096 patients (diabetes specialists: $n=437$ [39.9\%]; 
Table 1 Self-reported physician background information

\begin{tabular}{|c|c|c|c|c|c|c|}
\hline $\begin{array}{l}\text { Physician } \\
\text { characteristics }\end{array}$ & $\begin{array}{l}\text { Group 1: diabetes } \\
\text { specialists } \\
{[N=44]}\end{array}$ & $\begin{array}{l}\text { Group 2: GPwSIs } \\
{[N=23]}\end{array}$ & $\begin{array}{l}\text { Group 3: GPs } \\
{[N=46]}\end{array}$ & $\begin{array}{l}\text { Total sample } \\
{[N=113]}\end{array}$ & $\begin{array}{l}F \text {-value }(p \text {-value }) / p- \\
\text { value }^{\mathrm{a}}\end{array}$ & $\begin{array}{l}\text { Pairwise } \\
\text { comparisons }^{b}\end{array}$ \\
\hline $\begin{array}{l}\text { Number of years } \\
\text { physician has been } \\
\text { a practicing health } \\
\text { care provider [mean } \\
\text { (SD)] }\end{array}$ & $18.8(5.8)$ & $17.5(5.8)$ & $20.0(5.8)$ & $19.0(5.8)$ & $1.48(0.2326)$ & \\
\hline $\begin{array}{l}\text { Number of years } \\
\text { physician has been } \\
\text { managing or treating } \\
\text { patients with T2DM } \\
\text { [mean (SD)] }\end{array}$ & $15.6(5.1)$ & $15.6(5.2)$ & $17.2(5.3)$ & $16.3(5.2)$ & $1.32(0.2705)$ & \\
\hline $\begin{array}{l}\text { Number of T2DM } \\
\text { patients physician } \\
\text { sees in a typical } \\
\text { month [mean (SD)] }\end{array}$ & $136.0(52.9)$ & $103.5(49.7)$ & $86.7(43.9)$ & $109.3(53.2)$ & $11.75(<0.0001)$ & $\begin{array}{l}\text { A: } 0.0380 \\
\text { B: }<0.0001 \\
\text { C: } 0.4038\end{array}$ \\
\hline $\begin{array}{l}\text { Number of patients } \\
\text { physician initiated on } \\
\text { GLP-1 RA treatment } \\
\text { for T2DM in the } \\
\text { past } 6 \text { months [mean } \\
\text { (SD)] }\end{array}$ & $81.0(66.2)$ & $28.8(19.0)$ & $22.6(22.1)$ & $46.6(52.1)$ & $21.66(<0.0001)$ & $\begin{array}{l}\mathrm{A}:<0.0001 \\
\mathrm{~B}:<0.0001 \\
\mathrm{C}: 0.8641\end{array}$ \\
\hline $\begin{array}{l}\text { Geographic region of } \\
\text { practice }[n(\%)]\end{array}$ & & & & & 0.0288 & \\
\hline $\begin{array}{l}\text { Scotland and North- } \\
\text { ern Ireland }\end{array}$ & $6(13.6)$ & $1(4.3)$ & $1(2.2)$ & $8(7.1)$ & & \\
\hline $\begin{array}{l}\text { North England } \\
\text { (including Man- } \\
\text { chester) }\end{array}$ & $22(50.0)$ & $5(21.7)$ & $15(32.6)$ & $42(37.2)$ & & \\
\hline $\begin{array}{l}\text { South West England, } \\
\text { South Central } \\
\text { England, Midlands, } \\
\text { and Wales }\end{array}$ & $11(25.0)$ & $10(43.5)$ & $16(34.8)$ & $37(32.7)$ & & \\
\hline $\begin{array}{l}\text { London, East of } \\
\text { England, and South } \\
\text { East England }\end{array}$ & $5(11.4)$ & $7(30.4)$ & $14(30.4)$ & $26(23.0)$ & & \\
\hline $\begin{array}{l}\text { Number of patients } \\
\text { enrolled in the study } \\
\text { [mean (SD)] }\end{array}$ & $9.9(0.3)$ & $9.4(1.9)$ & $9.6(1.1)$ & $9.7(1.1)$ & $1.86(0.1599)$ & \\
\hline
\end{tabular}

$N$ number of patients with available data, T2DM type 2 diabetes mellitus, GPwSIs general practitioners with a special interest in diabetes, GPs general practitioners with no special interest in diabetes, GLP-1 glucagon-like peptide-1, RA receptor agonist, $S D$ standard deviation, $A N O V A$ analysis of variance

${ }^{a}$ For continuous variables, $F$ - and $p$-values from ANOVAs comparing the three groups are presented. For categorical variables, $p$-values from Chi-square tests are presented

${ }^{b}$ Pairwise comparisons with Scheffe's adjustment were conducted when the overall ANOVA model was statistically significant: A: group 1 vs. group 2; B: group 1 vs. group 3; C: group 2 vs. group 3

GPwSIs: $n=216$ [19.7\%]; and GPs: $n=443$ [40.4\%]) were included in the analysis sample.

The mean (SD) age of the patient sample was 55.1 years (11.7), the sample was $55.4 \%$ male, and the majority of the sample $(71.4 \%)$ was White (Table 2$)$. The mean (SD) age at the time of T2DM diagnosis was 47.1 years (11.3), and the mean age at the time of initiating GLP-1 RA treatment was 54.9 years (11.7). Mean (SD) body mass index (BMI) of the total sample was 35.2 (6.0), and the most common comorbidities were obesity ( $85.9 \%$ of the total sample) and cardiovascular disease $(29.5 \%)$. Although demographic characteristics generally appeared similar across patients whose data were reported by the three physician groups, some differences did emerge. For example, the average age at the time of T2DM diagnosis was younger for those treated by specialists compared with the other groups (45.6 years vs. 48.1 years for GPwSIs [ $p=0.0294$ ] and 48.2 years for GPs $[p=0.0026])$. GLP-1 RA initiation also happened 
Table 2 Demographic and clinical characteristics of patients whose data were extracted from medical records

\begin{tabular}{|c|c|c|c|c|c|c|}
\hline \multirow[t]{2}{*}{ Patient characteristics } & \multicolumn{3}{|c|}{$\begin{array}{l}\text { Patient data reported by physicians categorized } \\
\text { into three groups }\end{array}$} & \multirow[t]{2}{*}{$\begin{array}{l}\text { Total sample } \\
{[N=1096]}\end{array}$} & \multirow[t]{2}{*}{$\begin{array}{l}F \text {-value }(p \text {-value }) / p \text { - } \\
\text { value }^{\mathrm{a}}\end{array}$} & \multirow[t]{2}{*}{ Pairwise comparisons } \\
\hline & $\begin{array}{l}\text { Group 1: } \\
\text { diabetes } \\
\text { specialists } \\
{[N=437]}\end{array}$ & $\begin{array}{l}\text { Group 2: GPwSIs } \\
{[N=216]}\end{array}$ & $\begin{array}{l}\text { Group 3: GPs } \\
{[N=443]}\end{array}$ & & & \\
\hline $\begin{array}{l}\text { Age at the time of survey } \\
\text { completion [mean } \\
\text { (SD)] }\end{array}$ & $52.8(11.2)$ & $55.4(11.1)$ & $57.3(12.1)$ & $55.1(11.7)$ & $16.65(<0.0001)$ & $\begin{array}{l}\text { A: } 0.0309 \\
\text { B: }<0.0001 \\
\text { C: } 0.1267\end{array}$ \\
\hline $\begin{array}{l}\text { Age at the time of diag- } \\
\text { nosis [mean (SD)] }\end{array}$ & $45.6(10.7)$ & $48.1(11.5)$ & $48.2(11.5)$ & $47.1(11.3)$ & $6.92(0.0010)$ & $\begin{array}{l}\text { A: } 0.0294 \\
\text { B: } 0.0026 \\
\text { C: } 0.9897\end{array}$ \\
\hline $\begin{array}{l}\text { Age at GLP-1 RA initia- } \\
\text { tion [mean (SD)] }\end{array}$ & $52.6(11.1)$ & $55.1(11.1)$ & $57.1(12.1)$ & $54.9(11.7)$ & $17.00(<0.0001)$ & $\begin{array}{l}\text { A: } 0.0307 \\
\text { B: }<0.0001 \\
\text { C: } 0.1150\end{array}$ \\
\hline $\operatorname{Sex}[n(\%)]$ & & & & & 0.2422 & \\
\hline Male & $244(55.8)$ & $109(50.5)$ & $254(57.3)$ & $607(55.4)$ & & \\
\hline Female & $193(44.2)$ & $107(49.5)$ & $189(42.7)$ & $489(44.6)$ & & \\
\hline $\begin{array}{l}\text { Patient's ethnic/racial } \\
\text { origin }[n(\%)]\end{array}$ & & & & & $0.1031^{\mathrm{c}}$ & \\
\hline White & $331(75.7)$ & $140(64.8)$ & $311(70.2)$ & $782(71.4)$ & & \\
\hline African/Black & $19(4.3)$ & $19(8.8)$ & $22(5.0)$ & $60(5.5)$ & & \\
\hline $\begin{array}{l}\text { Asian or Pacific } \\
\text { Islander }\end{array}$ & $17(3.9)$ & $15(6.9)$ & $28(6.3)$ & $60(5.5)$ & & \\
\hline $\begin{array}{l}\text { North Africa and Mid- } \\
\text { dle Eastern }\end{array}$ & $7(1.6)$ & $5(2.3)$ & $7(1.6)$ & $19(1.7)$ & & \\
\hline $\begin{array}{l}\text { Indian subcontinent } \\
\text { (Indian, Pakistani, } \\
\text { Bangladeshi) }\end{array}$ & $59(13.5)$ & $35(16.2)$ & $71(16.0)$ & $165(15.1)$ & & \\
\hline Other & $2(0.5)$ & $1(0.5)$ & $2(0.5)$ & $5(0.5)$ & & \\
\hline Do not know & $2(0.5)$ & $1(0.5)$ & $2(0.5)$ & $5(0.5)$ & & \\
\hline BMI [mean (SD)] & $35.7(6.1)$ & $34.6(5.9)$ & $35.1(6.1)$ & $35.2(6.0)$ & $1.97(0.1399)$ & \\
\hline \multicolumn{7}{|c|}{ Comorbidities at the time of GLP-1 RA initiation $[n(\%)]$} \\
\hline $\begin{array}{l}\text { Congestive heart } \\
\text { failure }\end{array}$ & $13(3.0)$ & $8(3.7)$ & $7(1.6)$ & $28(2.6)$ & 0.2075 & \\
\hline Cardiovascular disease & $153(35.0)$ & $49(22.7)$ & $121(27.3)$ & $323(29.5)$ & 0.0022 & \\
\hline $\begin{array}{l}\text { Cardiovascular dis- } \\
\text { ease-microvascular } \\
\text { complications }\end{array}$ & $95(21.7)$ & $33(15.3)$ & $57(12.9)$ & $185(16.9)$ & 0.0016 & \\
\hline $\begin{array}{l}\text { Cardiovascular dis- } \\
\text { ease-macrovascular } \\
\text { complications }\end{array}$ & $86(19.7)$ & $21(9.7)$ & $78(17.6)$ & $185(16.9)$ & 0.0053 & \\
\hline Liver disease & $54(12.4)$ & $22(10.2)$ & $29(6.5)$ & $105(9.6)$ & 0.0130 & \\
\hline Obesity & $406(92.9)$ & $174(80.6)$ & $362(81.7)$ & $942(85.9)$ & $<0.0001$ & \\
\hline Renal disease & $70(16.0)$ & $40(18.5)$ & $68(15.3)$ & $178(16.2)$ & 0.5775 & \\
\hline $\begin{array}{l}\text { Patient had none of the } \\
\text { above comorbidities }\end{array}$ & $18(4.1)$ & $28(13.0)$ & $48(10.8)$ & $94(8.6)$ & $<0.0001$ & \\
\hline
\end{tabular}

$B M I$ body mass index, GLP-1 glucagon-like peptide-1, GPwSIs general practitioners with a special interest in diabetes, GPs general practitioners with no special interest in diabetes, $R A$ receptor agonist, $S D$ standard deviation, ANOVA analysis of variance

${ }^{a}$ For continuous variables, $F$ - and $p$-values from ANOVAs comparing the three groups are presented. For categorical variables, $p$-values from Chi-square tests are presented

'Pairwise comparisons with Scheffe's adjustment were conducted when the overall ANOVA model was statistically significant: A: group 1 vs. group 2; B: group 1 vs. group 3; C: group 2 vs. group 3

'Excluding the 'other' and 'don't know' groups 
Table 3 Treatment of patients whose data were extracted from medical records

\begin{tabular}{|c|c|c|c|c|}
\hline \multirow[t]{2}{*}{ Treatment characteristics } & \multicolumn{3}{|c|}{ Patient data reported by physicians categorized into three groups } & \multirow{2}{*}{$\begin{array}{l}\text { Total sample } \\
{[N=1096]}\end{array}$} \\
\hline & $\begin{array}{l}\text { Group 1: diabetes } \\
\text { specialists } \\
{[N=437]}\end{array}$ & $\begin{array}{l}\text { Group 2: GPwSIs } \\
{[N=216]}\end{array}$ & $\begin{array}{l}\text { Group 3: GPs } \\
{[N=443]}\end{array}$ & \\
\hline \multicolumn{5}{|l|}{ Type of GLP-1 RA initiated $[n(\%)]$} \\
\hline Exenatide extended-release & $48(11.0)$ & $25(11.6)$ & $42(9.5)$ & $115(10.5)$ \\
\hline Exenatide & $18(4.1)$ & $49(22.7)$ & $72(16.3)$ & $139(12.7)$ \\
\hline Albiglutide & $4(0.9)$ & $1(0.5)$ & & $5(0.5)$ \\
\hline Lixisenatide & $41(9.4)$ & $20(9.3)$ & $37(8.4)$ & $98(8.9)$ \\
\hline Dulaglutide & $130(29.7)$ & $18(8.3)$ & $63(14.2)$ & $211(19.3)$ \\
\hline Liraglutide & $196(44.9)$ & $103(47.7)$ & $229(51.7)$ & $528(48.2)$ \\
\hline \multicolumn{5}{|c|}{ Type of T2DM regimen immediately prior to GLP-1 RA initiation $[n(\%)]$} \\
\hline Oral only & $334(76.4)$ & $190(88.0)$ & $394(88.9)$ & $918(83.8)$ \\
\hline Injectable only & $2(0.5)$ & $4(1.9)$ & $8(1.8)$ & $14(1.3)$ \\
\hline Combination of oral and injectable medications & $94(21.5)$ & $15(6.9)$ & $36(8.1)$ & $145(13.2)$ \\
\hline $\begin{array}{l}\text { No medication was prescribed for T2DM prior to the } \\
\text { GLP-1 RA initiation }\end{array}$ & $7(1.6)$ & $7(3.2)$ & $5(1.1)$ & $19(1.7)$ \\
\hline
\end{tabular}

$G L P$-1 glucagon-like peptide-1, GPwSIs general practitioners with a special interest in diabetes, GPs general practitioners with no special interest in diabetes, $R A$ receptor agonist, $T 2 D M$ type 2 diabetes mellitus

at a younger age for patients treated by specialists than patients treated by the other physician types $(52.6$ years vs. 55.1 years for GPwSIs $[p=0.0307]$ and 57.1 years for GPs $[p<0.0001])$.

Physicians reported the type of GLP-1 RA that was initiated for each patient (Table 3 ). The most commonly prescribed GLP-1 RA was liraglutide $(n=528 ; 48.2 \%)$, followed by dulaglutide ( $n=211 ; 19.3 \%)$, exenatide $(n=139$; $12.7 \%)$, exenatide extended-release $(n=115 ; 10.5 \%)$, lixisenatide $(n=98 ; 8.9 \%)$, and albiglutide $(n=5 ; 0.5 \%)$. Compared with the other two physician groups, diabetes specialists reported a higher rate of initiating treatment with dulaglutide, which accounted for $29.7 \%$ of GLP-1 RA initiations prescribed by the specialists versus $8.3 \%$ and $14.2 \%$ in the other two groups (Table 3 ). For the majority of patients, the treatment regimen prior to GLP-1 RA initiation involved only oral medication (83.8\%), while $13.2 \%$ received a combination of oral and injectable treatment, and $1.3 \%$ were receiving an injectable-only regimen.

\subsection{Time from Diagnosis to First Glucagon-Like Peptide-1 Receptor Agonist (GLP-1 RA) Initiation}

The mean (SD) time from diagnosis to GLP-1 RA initiation was 7.8 years (6.9), and the median was 6.1 years (Table 4). The time between diagnosis and GLP-1 RA initiation ranged from a minimum of 0.0 years due to rounding (although all patients had at least 1 week between diagnosis and GLP-1 RA initiation) to a maximum of 52.9 years. There were 53 patients with more than 20 years between diagnosis and
GLP-1 RA initiation. The patient with a span of 52.9 years was 94 years of age at the time of GLP-1 RA initiation. The diabetes specialists and GPwSIs tended to prescribe GLP-1 RAs more quickly than the GPs (mean of 7.0 years between diagnosis and GLP-1 RA initiation for the first two groups, compared with 8.9 years for the GPs, $p<0.01$ ).

\subsection{Estimate of Clinical Inertia: Duration of Time Patients were not Under Control Prior to GLP-1 RA Initiation}

The purpose of this analysis was to examine the duration of time that patients did not maintain glycaemic control while remaining on a treatment regimen with oral medication prior to intensifying treatment with a GLP-1 RA (Table 5). This analysis was conducted with data from the 1063 patients (i.e. $97.0 \%$ of the total sample) whose treatment regimen prior to GLP-1 RA initiation included oral medication. This subset of 1063 patients included 918 patients treated with only oral medication and 145 patients treated with both oral and injectable medication.

With the HbA1c cut-off of $7.0 \%$ or $53 \mathrm{mmol} / \mathrm{mol}$, the mean (SD) number of consecutive months that the patients were not under control since starting the last oral treatment regimen prior to GLP-1 RA initiation was 18.9 (16.8), and the median was 13.5 . The mean and median durations were significantly different (shorter) for patients of diabetes specialists than for patients of GPs ( $p=0.01$ for means, and $p=0.04$ for medians). Although not statistically significant, diabetes specialists also had a shorter duration compared 
Table 4 Time from type 2 diabetes diagnosis to GLP-1 RA initiation

\begin{tabular}{|c|c|c|c|c|c|c|}
\hline \multirow{2}{*}{$\begin{array}{l}\text { Time (years) from diagnosis } \\
\text { to initiation of first GLP-1 } \\
\text { RA }\end{array}$} & \multicolumn{3}{|c|}{$\begin{array}{l}\text { Patient data reported by physicians categorized into } \\
\text { three groups }\end{array}$} & \multirow[t]{2}{*}{$\begin{array}{l}\text { Total sample } \\
{[N=1096]}\end{array}$} & \multirow{2}{*}{$\begin{array}{l}p \text {-value for } \\
\text { group } \\
\text { comparison }\end{array}$} & \multirow[t]{2}{*}{ Pairwise comparisons } \\
\hline & $\begin{array}{l}\text { Group 1: diabetes } \\
\text { specialists } \\
{[N=437]}\end{array}$ & $\begin{array}{l}\text { Group 2: GPwSIs } \\
{[N=216]}\end{array}$ & $\begin{array}{l}\text { Group 3: GPs } \\
{[N=443]}\end{array}$ & & & \\
\hline Mean (SD) & $7.0(5.9)$ & $7.0(6.4)$ & $8.9(7.9)$ & $7.8(6.9)$ & $<0.0001^{\mathrm{a}}$ & $\begin{array}{l}\text { A: } 0.9979 \\
\text { B: } 0.0003 \\
\text { C: } 0.0056\end{array}$ \\
\hline $\begin{array}{l}\text { Estimated median from KM } \\
\quad(95 \% \mathrm{CI})\end{array}$ & $5.6(5.10-6.38)$ & $5.3(4.50-6.45)$ & $6.7(6.03-7.52)$ & $6.1(5.60-6.47)$ & $<0.0001^{\mathrm{b}}$ & $\begin{array}{l}\text { A: } 0.6017 \\
\text { B: } 0.0002 \\
\text { C: } 0.0005\end{array}$ \\
\hline Minimum-maximum $^{\mathrm{c}}$ & $0.0-40.4$ & $0.0-48.2$ & $0.1-52.9$ & $0.0-52.9$ & & \\
\hline
\end{tabular}

GLP-1 glucagon-like peptide-1, GPwSIs general practitioners with a special interest in diabetes, GPs general practitioners with no special interest in diabetes, $R A$ receptor agonist, $S D$ standard deviation, $C I$ confidence interval, KM Kaplan-Meier, $A N O V A$ analysis of variance

${ }^{a}$ From ANOVA with Scheffe's post hoc pairwise comparisons

${ }^{\mathrm{b}}$ From the log-rank test

${ }^{\mathrm{c}}$ Minimum was 0.0 years due to rounding; however, all patients had at least 1 week between diagnosis and GLP-1 RA initiation

${ }^{\mathrm{d}}$ Pairwise comparisons: A: group 1 vs. group 2; B: group 1 vs. group 3; C: group 2 vs. group 3

Table 5 Duration of clinical inertia: time patients remained on their last oral treatment regimen with inadequate glycaemic control prior to GLP-1 RA initiation

\begin{tabular}{|c|c|c|c|c|c|c|}
\hline \multirow[t]{2}{*}{ Consecutive months } & \multicolumn{3}{|c|}{ Patient data reported by physicians categorized into three groups } & \multirow{2}{*}{$\begin{array}{l}\text { Total sample } \\
{[N=1063]^{\mathrm{a}}}\end{array}$} & \multirow{2}{*}{$\begin{array}{l}p \text {-value for } \\
\text { group } \\
\text { comparison }\end{array}$} & \multirow{2}{*}{$\begin{array}{l}\text { Pairwise } \\
\text { comparison }\end{array}$} \\
\hline & $\begin{array}{l}\text { Group 1: diabetes } \\
\text { specialists } \\
{[N=428]^{\mathrm{a}}}\end{array}$ & $\begin{array}{l}\text { Group 2: GPwSIs } \\
{[N=205]^{\mathrm{a}}}\end{array}$ & $\begin{array}{l}\text { Group 3: GPs } \\
{[N=430]^{\mathrm{a}}}\end{array}$ & & & \\
\hline \multicolumn{7}{|c|}{ With HbA1c cut-off of $>7.0 \%$ for inadequate glycaemic control } \\
\hline Mean (SD) & $16.7(16.6)$ & $20.1(16.3)$ & $20.4(17.1)$ & $18.9(16.8)$ & $0.0023^{\mathrm{c}}$ & $\begin{array}{l}\text { A: } 0.1151 \\
\text { B: } 0.0139 \\
\text { C: } 0.9983\end{array}$ \\
\hline $\begin{array}{l}\text { Estimated median } \\
\text { from KM }(95 \% \\
\text { CI) }\end{array}$ & $11.0(9.00-12.10)$ & $16.2(13.10-20.60)$ & $17.0(14.30-19.40)$ & $13.5(12.40-15.50)$ & $0.0428^{\mathrm{d}}$ & $\begin{array}{l}\text { A: } 0.2312 \\
\text { B: } 0.0383 \\
\text { C: } 0.4986\end{array}$ \\
\hline $\begin{array}{l}\text { Minimum-maxi- } \\
\text { mum }^{\mathrm{e}}\end{array}$ & $0.0-59.8$ & $0.0-58.0$ & $0.0-59.6$ & $0.0-59.8$ & & \\
\hline \multicolumn{7}{|c|}{ With HbA1c cut-off of $>7.5 \%$ for inadequate glycaemic control } \\
\hline Mean (SD) & $14.1(15.3)$ & $17.9(15.8)$ & $17.3(16.5)$ & $16.1(16.0)$ & $0.0030^{\mathrm{c}}$ & $\begin{array}{l}\text { A: } 0.0480 \\
\text { B: } 0.0381 \\
\text { C: } 0.9725\end{array}$ \\
\hline $\begin{array}{l}\text { Estimated median } \\
\text { from } \\
\mathrm{KM}(95 \% \mathrm{CI})\end{array}$ & $8.1(6.70-10.20)$ & $13.7(11.90-17.70)$ & $12.6(10.90-14.30)$ & $11.2(10.00-12.10)$ & $0.0167^{\mathrm{d}}$ & $\begin{array}{l}\text { A: } 0.0468 \\
\text { B: } 0.0248 \\
\text { C: } 0.8417\end{array}$ \\
\hline $\begin{array}{l}\text { Minimum-maxi- } \\
\text { mum }^{\mathrm{e}}\end{array}$ & $0.0-59.1$ & $0.0-58.0$ & $0.0-59.5$ & $0.0-59.5$ & & \\
\hline
\end{tabular}

GLP-1 glucagon-like peptide-1, GPwSIs general practitioners with a special interest in diabetes, GPs general practitioners with no special interest in diabetes, $R A$ receptor agonist, $S D$ standard deviation, $C I$ confidence interval, KM Kaplan-Meier, ANOVA analysis of variance, $H b A 1 c$ glycated haemoglobin

${ }^{a}$ Number of eligible patients with an oral treatment regimen within the 5 years prior to GLP-1 initiation (specialists: 428 of 437 ; GPwSIs: 205 of 216; GPs: 430 of 443)

${ }^{b}$ Pairwise comparisons: A: group 1 vs. group 2; B: group 1 vs. group 3; C: group 2 vs. group 3

${ }^{c}$ From ANOVA with Scheffe's post hoc pairwise comparisons

${ }^{\mathrm{d}}$ From the log-rank test

${ }^{\mathrm{e}}$ Minimum was 0.0 years due to rounding; however, all patients had at least 1 week between diagnosis and GLP-1 RA initiation 
with the GPwSI group (16.7 months vs. 20.1 months) (Table 5).

With the higher HbA1c cut-off of $>7.5 \%$ or $58 \mathrm{mmol} /$ mol, the mean (SD) number of consecutive months that patients were not under control since starting the last oral treatment regimen prior to GLP-1 RA initiation was 16.1 (16.0), and the median was 11.2. As with the lower cut-off described above, the mean duration was shorter for diabetes specialists than the other two groups. With the higher cutoff, both differences were statistically significant (Table 5).

The KM curve for duration from uncontrolled HbA1c to first GLP-1 RA initiation (by type of treating physician for both $\mathrm{HbAlc}$ cut-off values) is presented in Fig. 3. The separation between the curve for the specialists (i.e. endocrinologists and diabetologists) and the curves for the other two groups (GPwSI and GPs) highlights the shorter duration of inertia (i.e. delay in GLP-1 RA initiation) among diabetes specialists compared with the other two groups.

\section{Discussion}

This is the first study to examine the timing of intensification of treatment for T2DM with GLP-1 RAs, and the analysis yielded two key findings. First, the results provide an indication of the time from diagnosis to treatment intensification with injectable GLP-1 RAs. In the current sample, the median duration prior to the first GLP-1 RA initiation was 6 years. This appears to be a shorter period of time than would be expected for intensification to insulin based on previous research [15].

Second, this study provides the first data on clinical inertia associated with GLP-1 RAs. Treatment guidelines recommend that treatment intensification should be considered after 3-6 months of consistently insufficient glycaemic control $[3,4]$. However, patients had HbA1c values over 7.0\% for a median of 13.5 months, and over $7.5 \%$ for a median of 11.2 months prior to switching from their last oral regimen to a GLP-1 RA. These results suggest that patients remained on an oral regimen longer than recommended. Intensification with a GLP-1 RA could have helped them achieve glycaemic control. Whereas previous studies have demonstrated clinical inertia prior to initiation of insulin therapy $[8,9,15]$, the current study adds to this body of literature by suggesting that there is also inertia prior to initiating GLP-1 RAs.

Despite the potential similarity between GLP-1 RA inertia and insulin inertia, a direct comparison between time to insulin initiation and time to GLP-1 RA initiation is difficult due to methodological differences between the current study and previous studies. The current study gathered data from medical records to ensure availability of dates of diagnosis and $\mathrm{HbA} 1 \mathrm{c}$ evaluations, whereas previous studies on the duration of insulin inertia have generally analysed data from large databases. However, a recently published systematic review revealed wide variation in the duration of insulin inertia, ranging up to 7.2 years $[9,15]$. Based on the current results, it seems likely that GLP-1 RA inertia may be shorter than the average delay in treatment intensification with insulin. Future research examining the time to initiation of both insulin and GLP-1 RAs in the same sample, using the same methodology, would be helpful in understanding differences in inertia related to these two treatment classes.

Our findings complement the results of a previously published online physician survey that identified a range of factors that commonly cause hesitation when prescribing GLP-1 RAs, particularly among general practice physicians, almost one-quarter of whom reported that they did not have sufficient knowledge to prescribe GLP-1 RAs [23]. Reasons for hesitating when prescribing GLP-1 RAs included injectable administration, cost, potential gastrointestinal adverse effects, and the fact that medications in this class were not considered first-line therapy when the online survey was conducted in 2014. The survey also identified the common reasons for prescribing GLP-1 RAs, including good efficacy, association with weight loss, and low hypoglycaemia risk. Although the current study was not designed to assess reasons for inertia, the findings add to the published survey results by quantifying and demonstrating the extent of the inertia that may be related to the concerns previously reported by physicians.

Furthermore, as also found in a previously published physician survey [23], inertia was most pronounced among the general practice physicians. Compared with patients treated by specialists, patients treated by GPs had a significantly longer duration of time with insufficient glycaemic control prior to GLP-1 RA initiation (regardless of which HbA1c cut-off value was used for insufficient glycaemic control). These results suggest that diabetes specialists may tend to intensify treatment more quickly than general practice physicians.

Several limitations of this study should be acknowledged. Data were obtained from a subset of physicians willing to review and report medical record data, therefore the results may not be generalizable to all T2DM patients or all physicians who prescribe GLP-1 RAs in the UK. It is possible that the physicians who agreed to participate in this study were those who were more interested in GLP-1 RAs or more inclined to prescribe medications from this class. In addition, $\mathrm{HbA} 1 \mathrm{c}$ measures were only reported for the 5 years prior to GLP-1 RA initiation, which could lead to an underestimate of the burden of glycaemic control if some patients' HbA1c values were above glycaemic control targets for a longer period of time.

Due to the nature of chart review studies, some $\mathrm{HbA1c}$ measures may have also been missing from the charts. For example, patients may have had their HbA1c checked by 


\section{Product-Limit Survival Estimates}

With Number of Subjects at Risk

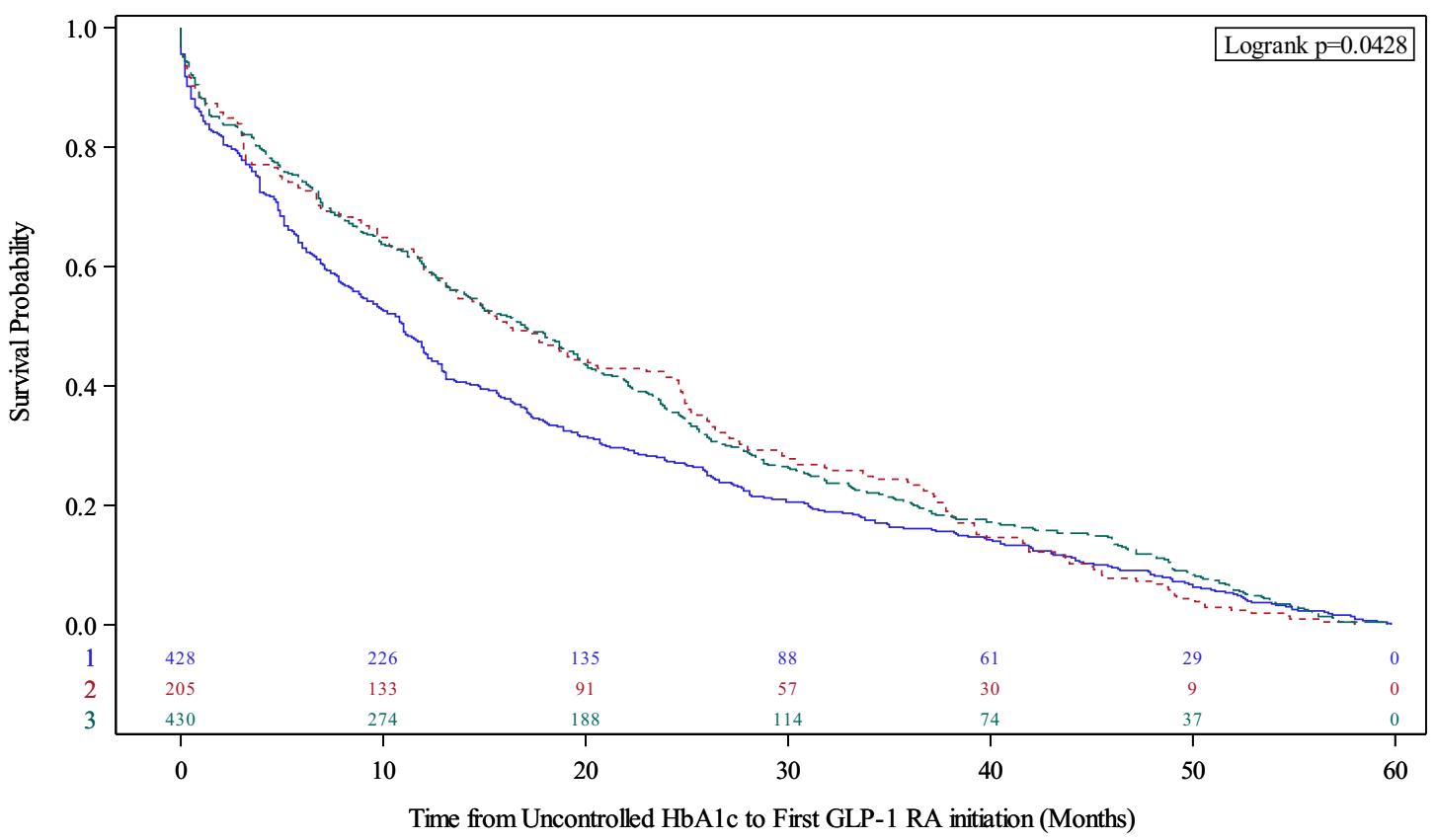

Product-Limit Survival Estimates

With Number of Subjects at Risk

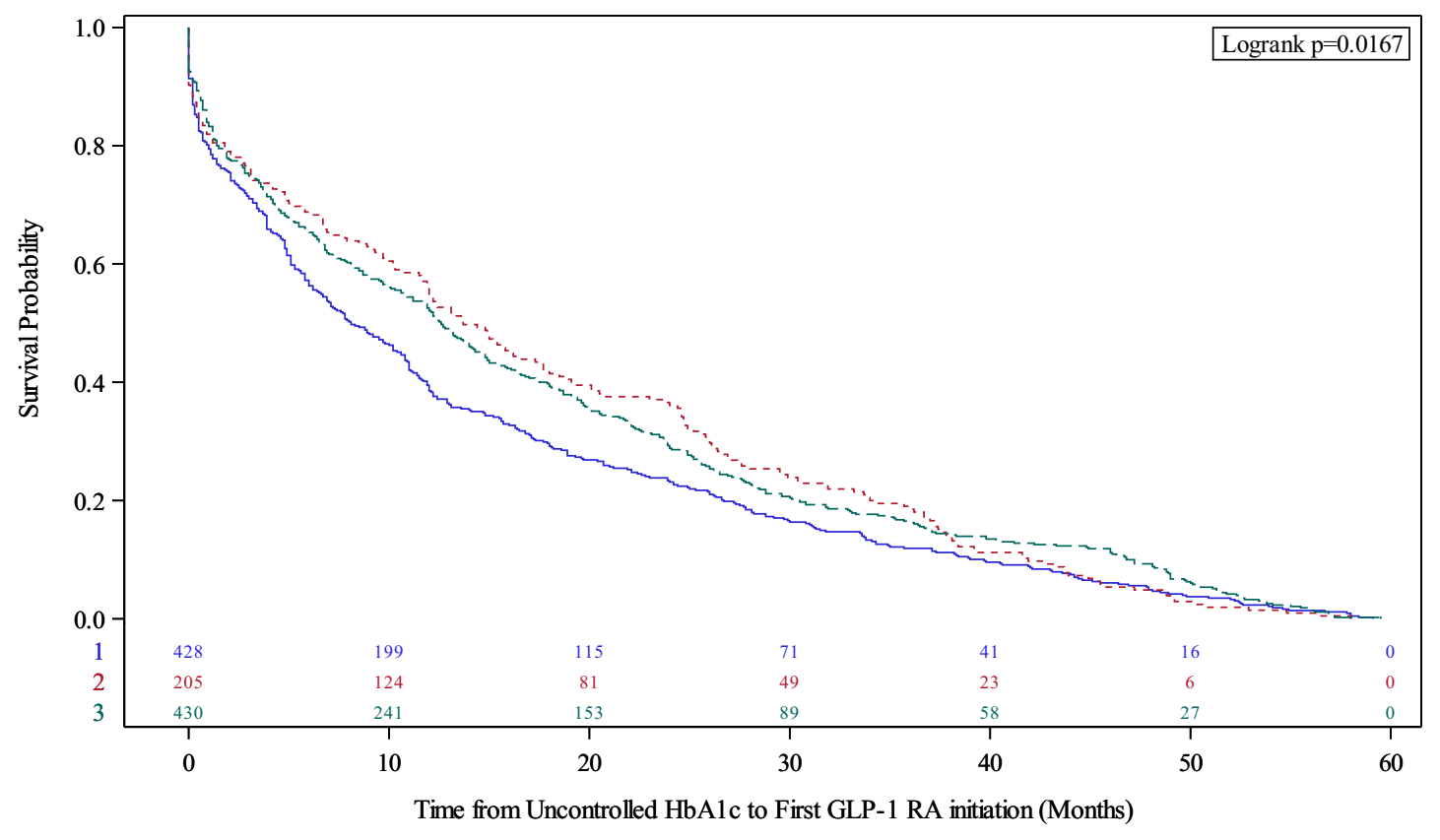

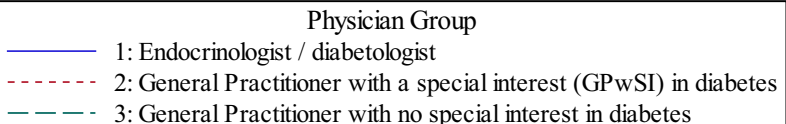

Fig. 3 Kaplan-Meier curves for duration of clinical inertia: time patients remained on their last oral treatment regimen with inadequate glycaemic control prior to GLP-1 RA initiation. GLP-1 glucagon-like peptide-1, HbAlc glycated haemoglobin, $R A$ receptor agonist 
another health care provider, and the results may not have been included in the medical records reviewed for the current study. Missing 'above target' HbAlc values could lead to an underestimate of clinical inertia, whereas missing 'below target' HbA1c values could result in an overestimate of inertia. Specific details about the treatment regimen prior to the GLP-1 RA initiation are also unavailable. Although physicians reported the type of treatment regimen (i.e. oral medication, injectable medication, or a combination approach), they were not asked for the specific name or class of each drug that was prescribed. Therefore, the current study cannot provide insight into whether specific medications tend to be associated with inertia. Another possible issue is that treatment options other than a GLP-1 RA may have been considered, which could lead to confounding factors when interpreting the duration of inertia associated specifically with GLP-1 RAs.

Geographical representation should also be considered. Efforts were made to locate physicians across the UK to maximise geographical diversity; however, only eight physicians (7.1\%) were from Scotland and Northern Ireland, while the majority of the physicians were from England. Thus, the data are not geographically representative of the entire UK.

\section{Conclusions}

Findings from this study highlight that there may be patients with T2DM who would benefit from more rapid treatment intensification. If intensified treatment were initiated earlier and patients achieve glycaemic control as a result, then this would reduce the risks for many short- and long-term health complications such as hypoglycaemia and microvascular and macrovascular complications. For patients who are not achieving adequate glycaemic control with oral medication alone, GLP-1 RAs provide an option for treatment intensification other than insulin.

Authorship All named authors meet the International Committee of Medical Journal Editors (ICMJE) criteria for authorship for this article, take responsibility for the integrity of the work as a whole, and have given their approval for this version to be published. DS, LM, JJ, and KB directed aspects of the study; KN, LEGP, RY, and SWH made substantive contributions to the study design, analysis, and interpretation; $\mathrm{LM}, \mathrm{JJ}$, and $\mathrm{KB}$ wrote this manuscript, and all other authors provided input, comments, and final approval.

Medical Writing, Editorial, and Other Assistance The authors would like to thank Brooke Currie for medical writing; Valerie Derrien and AplusA Healthcare Market Research for assistance with data collection; and Amara Tiebout for editorial assistance.

Compliance with Ethics Guidelines The authors received the approval of an Institutional Review Committee (Ethical and Independent Review Services IRB; 23 May 2017; Protocol 17059-01). All procedures performed in the study involving human participants were in accordance with the ethical standards of the institutional and/or national research committee and with the 1964 Helsinki declaration and its later amendments or comparable ethical standards. Informed consent was obtained from all individual participants included in the study.

Former Presentations Some of the findings reported in this study were presented at the European Association for the Study of Diabetes 54th Annual Meeting, Berlin, Germany, 1-5 October 2018.

\section{Compliance with Ethical Standards}

Funding Funding for this study was provided by Eli Lilly and Company (Grant no. EVA-19867), Indianapolis, IN, USA.

Disclosures Kirsi Norrbacka, Luis-Emilio García-Pérez, Syed Wasi Hassan, and Kristina S. Boye are employees of Eli Lilly, who provided funding for this study. Dara Stein, Louis Matza, Ren Yu, and Jessica Jordan are employed by Evidera, a company that received funding from Eli Lilly for time spent on this research. All aspects of the study design, interpretation, and manuscript were determined by the authors.

Open Access This article is distributed under the terms of the Creative Commons Attribution-NonCommercial 4.0 International License (http://creativecommons.org/licenses/by-nc/4.0/), which permits any noncommercial use, distribution, and reproduction in any medium, provided you give appropriate credit to the original author(s) and the source, provide a link to the Creative Commons license, and indicate if changes were made.

\section{References}

1. American Diabetes Association (ADA). Introduction: Standards of Medical Care in Diabetes-2018. Diabetes Care. 2018;41(Suppl 1):S1-2.

2. Garber AJ, Abrahamson MJ, Barzilay JI, Blonde L, Bloomgarden ZT, Bush MA, et al. Consensus Statement by the American Association of Clinical Endocrinologists and American College of Endocrinology on the comprehensive type 2 diabetes management algorithm-2018 executive summary. Endocr Pract. 2018;24(1):91-120.

3. Inzucchi SE, Bergenstal RM, Buse JB, Diamant M, Ferrannini E, Nauck M, et al. Management of hyperglycaemia in type 2 diabetes, 2015: a patient-centred approach. Update to a position statement of the American Diabetes Association and the European Association for the Study of Diabetes. Diabetologia. 2015;58(3):429-42.

4. National Institute for Health and Care Excellence (NICE). Type 2 diabetes in adults: management-NICE guideline [NC28]. London: NICE. Published December 2015, Updated May 2017. https ://www.nice.org.uk/guidance/ng28. Accessed 23 Aug 2017.

5. Scottish Intercollegiate Guidelines Network (SIGN). Pharmacological management of glycaemic control in people with type 2 diabetes. SIGN, Edinburgh. November 2017. https://www.sign. ac.uk/assets/sign154.pdf. Accessed 13 Dec 2018.

6. Brod M, Kongso JH, Lessard S, Christensen TL. Psychological insulin resistance: patient beliefs and implications for diabetes management. Quality Life Res. 2009;18(1):23-32.

7. Harris SB, Kapor J, Lank CN, Willan AR, Houston T. Clinical inertia in patients with T2DM requiring insulin in family practice. Can Fam Physician. 2010;56(12):e418-24.

8. Khunti K, Nikolajsen A, Thorsted BL, Andersen M, Davies MJ, Paul SK. Clinical inertia with regard to intensifying therapy in 
people with type 2 diabetes treated with basal insulin. Diabetes Obes Metab. 2016;18(4):401-9.

9. Khunti K, Wolden ML, Thorsted BL, Andersen M, Davies MJ. Clinical inertia in people with type 2 diabetes: a retrospective cohort study of more than 80,000 people. Diabetes Care. 2013;36(11):3411-7.

10. Mata-Cases M, Franch-Nadal J, Real J, Gratacos M, Lopez-Simarro F, Khunti K, et al. Therapeutic inertia in patients treated with two or more antidiabetics in primary care: factors predicting intensification of treatment. Diabetes Obes Metab. 2018;20(1):103-12.

11. Peyrot M, Rubin RR, Lauritzen T, Skovlund SE, Snoek FJ, Matthews DR, et al. Resistance to insulin therapy among patients and providers: results of the cross-national Diabetes Attitudes, Wishes, and Needs (DAWN) study. Diabetes Care. 2005;28(11):2673-9.

12. Polonsky WH, Fisher L, Guzman S, Villa-Caballero L, Edelman SV. Psychological insulin resistance in patients with type 2 diabetes: the scope of the problem. Diabetes Care. 2005;28(10):2543-5.

13. Shah BR, Hux JE, Laupacis A, Zinman B, van Walraven C. Clinical inertia in response to inadequate glycemic control: do specialists differ from primary care physicians? Diabetes Care. 2005;28(3):600-6.

14. Hayes RP, Fitzgerald JT, Jacober SJ. Primary care physician beliefs about insulin initiation in patients with type 2 diabetes. Int J Clin Pract. 2008;62(6):860-8.

15. Khunti K, Gomes MB, Pocock S, Shestakova MV, Pintat S, Fenici $\mathrm{P}$, et al. Therapeutic inertia in the treatment of hyperglycaemia in patients with type 2 diabetes: a systematic review. Diabetes Obes Metab. 2018;20(2):427-37.

16. Reach G, Pechtner V, Gentilella R, Corcos A, Ceriello A. Clinical inertia and its impact on treatment intensification in people with type 2 diabetes mellitus. Diabetes Metab. 2017;43(6):501-11.

17. Ziemer DC, Miller CD, Rhee MK, Doyle JP, Watkins C Jr, Cook $\mathrm{CB}$, et al. Clinical inertia contributes to poor diabetes control in a primary care setting. Diabetes Educ. 2005;31(4):564-71.

18. Nakar S, Yitzhaki G, Rosenberg R, Vinker S. Transition to insulin in type 2 diabetes: family physicians' misconception of patients' fears contributes to existing barriers. J Diabetes Complications. 2007;21(4):220-6.
19. Tan AM, Muthusamy L, Ng CC, Phoon KY, Ow JH, Tan NC. Initiation of insulin for type 2 diabetes mellitus patients: what are the issues? A qualitative study. Singap Med J. 2011;52(11):801-9.

20. Zografou I, Strachan M, McKnight J. Delay in starting insulin after failure of other treatments in patients with type 2 diabetes mellitus. Hippokratia. 2014;18(4):306-9.

21. Abu Hassan H, Tohid H, Mohd Amin R, Long Bidin MB, Muthupalaniappen L, Omar K. Factors influencing insulin acceptance among type 2 diabetes mellitus patients in a primary care clinic: a qualitative exploration. BMC Fam Pract. 2013;14:164.

22. Hugie C, Waterbury NV, Alexander B, Shaw RF, Egge JA. Adding glucose-lowering agents delays insulin initiation and prolongs hyperglycemia. Am J Manag Care. 2016;22(4):e134-40.

23. Matza LS, Curtis SE, Jordan JB, Adetunji O, Martin SA, Boye KS. Physician perceptions of GLP-1 receptor agonists in the UK. Curr Med Res Opin. 2016;32(5):857-64.

24. Aroda VR, Ratner R. The safety and tolerability of GLP-1 receptor agonists in the treatment of type 2 diabetes: a review. Diabetes Metab Res Rev. 2011;27(6):528-42.

25. Inzucchi SE, Bergenstal RM, Buse JB, Diamant M, Ferrannini E, Nauck M, et al. Management of hyperglycemia in type 2 diabetes: a patient-centered approach: position statement of the American Diabetes Association (ADA) and the European Association for the Study of Diabetes (EASD). Diabetes Care. 2012;35(6):1364-79.

26. Aroda VR, Henry RR, Han J, Huang W, DeYoung MB, Darsow T, et al. Efficacy of GLP-1 receptor agonists and DPP-4 inhibitors: meta-analysis and systematic review. Clin Ther. 2012;34(6):1247-58.

27. Hall GC, McMahon AD, Dain MP, Wang E, Home PD. Primarycare observational database study of the efficacy of GLP-1 receptor agonists and insulin in the UK. Diabet Med. 2013;30(6):681-6.

28. Trujillo JM, Nuffer W, Ellis SL. GLP-1 receptor agonists: a review of head-to-head clinical studies. Ther Adv Endocrinol Metab. 2015;6(1):19-28.

29. Nichols GA, Koo YH, Shah SN. Delay of insulin addition to oral combination therapy despite inadequate glycemic control: delay of insulin therapy. J Gen Intern Med. 2007;22(4):453-8. 